\title{
Responsible conduct in chemical safety and security practices and its development in Malaysia
}

\begin{abstract}
The Malaysian economy has expanded rapidly since its independence in 1957, spurring the growth of the chemical-related industries, and the research and development activities. In view of this, it is essential to have the educational tools, guidance and best chemical practices in the chemical safety and security management. This chapter provides an overview of the responsible conducts in chemical practices in Malaysia, which covers four major topics: (1) chemical safety at the workplace; (2) chemical security in Malaysia; (3) responsible conduct of research, and finally (4) chemical safety education at Malaysian higher education institutions. Each topic comprehensively discusses various aspects of chemical safety and security, and the good practices, to reflect on the implementation and enforcement mechanisms in Malaysia. This chapter was written in a simple manner for easy understanding and hence, is suitable for chemistry practitioners at all levels, especially those interested in chemical safety and security practices and its development in Malaysia.
\end{abstract}

